\title{
Efectos del secado en punto crítico y secado en terbutanol en el tamaño de levaduras y eritrocitos humanos
}

\author{
José B. Yung ${ }^{1}$, Francisco J. Leal ${ }^{2}$, Francisco Hernández ${ }^{3}$, Julio García ${ }^{3}$, María R. Navarrete ${ }^{4}$
}

\begin{abstract}
Resumen
Uno de los problemas más frecuentes observados en muestras biológicas al microscopio de rastreo (SEM) es la disminución de tamaño de los especímenes, lo cual se ha asociado con el método de secado. En el caso de secado en punto crítico (SPC), esta reducción se calcula entre 20 y $80 \%$, pero, para el secado en terbutanol (STB) aún no se ha calculado. Se estudió el tamaño de las levaduras de Candida albicans y Phaeoannelomyces werneckii y de eritrocitos humanos procesados para SEM mediante SPC y STB, y contraste de fases. Las células se lavaron tres veces con amortiguador de fosfatos y se fijaron con glutaraldehído al 2,5\% en el mismo amortiguador a $4{ }^{\circ} \mathrm{C}$ por $2 \mathrm{~h}$. Se procesaron por duplicado sobre membranas policatiónicas de poli-L-lisina, se deshidrataron y se secaron en SPC y STB; se cubrieron con 200 A de oro y se analizaron al SEM (Hitachi S-570). El tamaño real se obtuvo en el microscopio de contraste de fases. Los resultados mostraron que, a pesar de las variaciones morfológicas presentes en las células estudiadas, hubo una disminución del 34,4 y $21,3 \%$ aproximadamente en el tamaño de los eritrocitos procesados por SPC y STB, respectivamente. Se discuten las variaciones en el tamaño del espécimen durante el procesamiento para SEM.
\end{abstract}

\section{Summary}

One of the most frequently reported problems when using the scanning electron microscope (SEM) to observe biological samples, is the decrease of the specimen size, a problem which has been associated with the chosen method of drying. In the case of critical drying point (CDP), this reduction is calculated at between $20 \%$ and $80 \%$, but has still not been calculated for the terbutyl alcohol freezedrying method (TFD). The size of Candida albicans and Phaeonnelomyces werneckii yeasts and processed human erythrocytes were studied by SEM using CDP, TFD and phase-contrast.

The cells were washed three times with a phosphate buffer and fixed with $2.5 \%$ glutaraldehyde in the same buffer at $4^{\circ} \mathrm{C}$ for 2 hours. They were processed in duplicate over polycationic membranes of poly-L-lysine, dehydrated and dried using CDP and TFD. They were covered with $200 \mathrm{~A}$ of gold and analyzed in the SEM. The real size was obtained in the phase-contrast microscope. The results showed that in spite of

\footnotetext{
1 Laboratorio de Investigación Clínica, Departamento de Ciencias Biológicas, Universidad de los Andes; Laboratorio de Inmunología, Hospital de San José, Santafé de Bogotá, D.C., Colombia.

2 Laboratorio de Inmunología y Alergia, Hospital Infantil Universitario Lorencita Villegas de Santos, Santafé de Bogotá, D.C., Colombia.

3 Facultad de Microbiología, Universidad de Costa Rica, San José, Costa Rica.

4 Laboratorio Clínico, Hospital Pediátrico Universitario de La Misericordia, Santafé de Bogotá, D.C., Colombia.
} 
the morphological variations presented in the studied cells, there was a shrinking of approximately $34.4 \%$ and $21.3 \%$ in the size of the eryhrocytes processed by CDP and TFD respectively. The variations of specimen size during the SEM process are discussed.

El microscopio electrónico de rastreo (MER) ha sido ampliamente utilizado para estudios morfológicos de diyersos tipos de células y tejidos, tanto en estados normales y patológicos como bajo condiciones experimentales; pero su uso ha sido limitado en análisis cuantitativos de área y volumen celular debido a las variaciones significativas en el tamaño de los especímenes, lo cual se ha asociado a los tratamientos previos empleados durante el procesamiento. Se ha estudiado el efecto de los diversos fijadores, sus concentraciones, las de los agentes deshidratantes y sobre todo de los métodos de secado, ya sea en tejidos animales, vegetales, esporas de hongos o células aisladas, entre otros (Boyde \& Boyde 1980, Eskelinen \& Saukko 1983, Beckett \& Porter 1984). Los métodos de secado han sido los más comúnmente involucrados como causantes del arrugamiento y disminución del tamaño del espécimen. En el caso del secado en punto crítico (SPC), esta reducción se ha calculado entre $20-80 \%$, pero, en el caso de secado con terbutanol (STB), esta reducción aún no se ha evaluado. El presente trabajo pretende calcular y comparar el efecto del SPCy STB en el tamaño de Candida albicans y Phaeoannelomyces (Aereobasidium) werneckii y de eritrocitos humanos durante el procesamiento para MER y microscopio de contraste de fases (MCF).

\section{Material y métodos}

Células: se estudiaron una cepa de $C$. albicans (Ch-10) y una de $P$. werneckii (C-62) de la micoteca del Centro de Micología de la Universidad de Costa Rica. Los análisis se hicieron a partir de cultivos frescos de 24-48 horas incubados a $22^{\circ} \mathrm{C}$ en agar Sabouraud. Los eritrocitos se obtuvieron de una muestra de sangre venosa de uno de los autores (JY), tomada sin torniquete y con EDTA como anticoagulante. Los ensayos se realizaron inmediatamente después de la donación.

MER: las células estudiadas se lavaron tres veces con amortiguador de fosfatos (AF) $0,1 \mathrm{M} \mathrm{pH}$
$7,2-7,4$, centrifugando a $2.000 \mathrm{rpm}$ por 10 minutos. Después del último lavado, se fijó el botón de células con glutaraldehído al 2,5\% agregándolo gota a gota con agitación constante y se dejó por $2 \mathrm{~h}$ a temperatura ambiente con rotación continua. Las levaduras se colocaron a $4^{\circ} \mathrm{C}$. Después de la fijación, se lavaron tres veces con AF y se procesaron por duplicado sobre membranas policatiónicas de poli-L-lisina sobre sustratos de vidrio sin agarosa (Hernández et al. 1986), se deshidrataron y se secaron en SPC con etanol- $\mathrm{CO}_{2}$ (HITACHI HCP-2), evacuando a una velocidad de un litro por minuto, y en secado por congelación-sublimación (freeze drying, FD) con terbutanol (Freeze Dryer VFD-20). Las láminas de vidrio se observaron en un microscopio estereoscópico y se montaron sobre bases de aluminio para MER con puentes de pintura de plata; se cubrieron con $200 \AA$ de oro (cobertor iónico con magneto, EIKO IB-3) por dos minutos $(0,05$ Torr, $10 \mathrm{~mA}-350 \mathrm{~V})$ para aumentar su reflectividad electrónica y se observaron el MER (HITACHI S-570) a $15 \mathrm{KV}$, con una resolución de $30 \AA$. Las fotos se tomaron a una distancia de trabajo de $11 \mathrm{~mm}$, sin inclinación, a magnificaciones entre 900X a 10.000X con película Kodak VP-120 (Verichrome Pan Film) ISO 125.

MCF: las células, después de los lavados posteriores a la fijación, se colocaron entre porta y cubreobjetos en AF para evaluar el efecto del glutaraldehído (GA) durante el proceso de fijación. Las medidas control se hicieron en células lavadas tres veces con solución salina isotónica $(0,9 \%)$, centrifugando a $200 \mathrm{rpm}$ por 10 minutos, sin fijar. Las fotografías se tomaron con película Kodak (Panatomic-X Film) isO 32 en un fotomicroscopio (NIKON Optiphot), a una magnificación de 400X.

Análisis estadístico: los especímenes, eritrocitos o levaduras, se midieron directamente sobre las fotografías con un vernier (calibrador). En el caso de los eritrocitos, se midió el diámetro de aquéllos que no presentaran alteraciones mor- 
fológicas evidentes y en las levaduras se seleccionaron las células sin gemación. Para propósitos de medición, se asumió que los glóbulos rojos eran circulares, las formas de $C$. albicans esféricas y las de $P$. werneckii elipsoides; en este último caso, se midieron los ejes longitudinal y transversal. Para cada tipo de ensayo se hicieron las mediciones por triplicado y se tomó el promedio de cada una. Se aplicó la prueba t de Student para la comparación entre medias, con un grado de confianza del $99 \%$.

\section{Resultados}

En la tabla 1 se muestran los datos obtenidos de los diámetros medidos para las células observadas al MCF sin fijar (NF) y fijadas con GA y al MER secadas por SPC y STB.

Tabla 1. Diámetros de las células estudiadas observadas en microscopio de contraste de fases y electrónico de rastreo

\begin{tabular}{|c|c|c|c|c|}
\hline & \multirow{2}{*}{$\begin{array}{c}\text { M. CONTRASTE } \\
\text { NF }\end{array}$} & \multirow{2}{*}{ FASE } & M. ELECTRONICO & \multirow{2}{*}{$\begin{array}{c}\text { RASTREO } \\
\text { STB }\end{array}$} \\
\hline & & & SPC & \\
\hline \multicolumn{5}{|l|}{ Eritrocitos } \\
\hline$n$ & 60,0 & 18,0 & 45,0 & 63,0 \\
\hline$x(\mu \mathrm{m})$ & 8,6 & 8,2 & 5,6 & 6,7 \\
\hline 2DS $(\mu \mathrm{m})$ & 1,58 & 1,28 & 0,78 & 1,48 \\
\hline Rango $(\mu \mathrm{m})$ & $7,1-10,3$ & $7,2-9,0$ & $4,9-6,4$ & $4,8-8,5$ \\
\hline \multicolumn{5}{|l|}{ C. albicans } \\
\hline$n$ & 63,0 & 37,0 & 100,0 & 100,0 \\
\hline$x(\mu \mathrm{m})$ & 6,1 & 6,3 & 3,0 & 3,2 \\
\hline $2 \mathrm{DS}(\mu \mathrm{m})$ & 2,26 & 2,54 & 1,26 & 1,36 \\
\hline Rango $(\mu \mathrm{m})$ & $3,5-9,4$ & $3,9-9,5$ & $1,1-4,4$ & $1,7-1,5.2$ \\
\hline \multicolumn{5}{|l|}{$\begin{array}{l}P \text {. werneckii } \\
\text { Longitudinal }\end{array}$} \\
\hline$n$ & 74,0 & 26,0 & 73,0 & 80,0 \\
\hline$x(\mu \mathrm{m})$ & 9,0 & 9,8 & 6,6 & 7,6 \\
\hline 2DS $(\mu \mathrm{m})$ & 3,46 & 3,44 & 2,38 & 3,9 \\
\hline Rango $(\mu \mathrm{m})$ & $4,7-14,1$ & $7,4-15,0$ & $3,7-9,0$ & $3,5-12,2$ \\
\hline \multicolumn{5}{|l|}{ Transversal } \\
\hline$n$ & 74,0 & 26,0 & 73,0 & 80,0 \\
\hline$x(\mu \mathrm{m})$ & 5,0 & 5,3 & 2,65 & 2,8 \\
\hline $2 \mathrm{DS}(\mu \mathrm{m})$ & 1,5 & 1,0 & 1,4 & 1,44 \\
\hline Rango $(\mu \mathrm{m})$ & $3,6-7,9$ & $4,1-6,5$ & $1,4-4,1$ & $1,3-4,1$ \\
\hline
\end{tabular}

NF: no fijados

GA: fijados con glutaraldehído

SPC: secado en punto crítico

STB: secado en terbutanol
En la tabla 2 se muestra el porcentaje de reducción para cada uno de los métodos de secado en las células estudiadas.

En este estudio, el secado mediante PC y TB preservó la morfología de las células (figuras 1 a 12) pero disminuyó significativamente $(p<0,005)$ su volumen en relación con las mediciones control, hechas de las células al MCF sin previa fijación. EI SPC presentó en todos los casos un porcentaje de reducción significativamente mayor que el STB $(p<0,005)$.

Se observó, además, un incremento significativo $(p<0,01)$ en el volumen de las células fijadas con GA de $3,3 \%$ para $C$. albicans, $8,9 \%$ para el diámetro longitudinal de $P$. werneckii y $6 \%$ para el diámetro transversal.

Tabla 2. Porcentaje de reducción en las células secadas en punto crítico y terbutanol

\begin{tabular}{lcc}
\hline Celulas & $\begin{array}{c}\text { \%de reducción enMER } \\
\text { SPC }\end{array}$ & STB \\
\hline Eritrocitos & & \\
C. albicans & 39,9 & 22,1 \\
P. werneckii & 50,8 & 47,5 \\
Longitudinal & 26,7 & 15,6 \\
Transversal & 47,0 & 44,0 \\
\hline
\end{tabular}

MER: microscopio electrónico de rastreo

\section{Discusión}

A pesar de la variedad morfológica entre las células estudiadas y aun entre las levaduras de la misma especie, se observó al igual que se había descrito en otros estudios, una considerable reducción del volumen de los especímenes procesados por SPC y STB, lo cual se demuestra por una reducción del diámetro de las células. Boyde y Boyde (1980), usando extremidades embrionarias de ratón, mostraron una reducción del volumen post-SPC de aproximadamente $40 \%$ para tejidos fijados con GA y $44 \%$ para tejidos postfijados con $\mathrm{OsO}_{2}$. También observaron una mayor reducción en SPC que en FD. Eskelinen y Sakkuro (1983) han informado una reducción del $24 \%$ para eritrocitos normales procesados con SPC, lo cual es considerablemente menor a lo encontrado en nuestro estudio que muestra una 

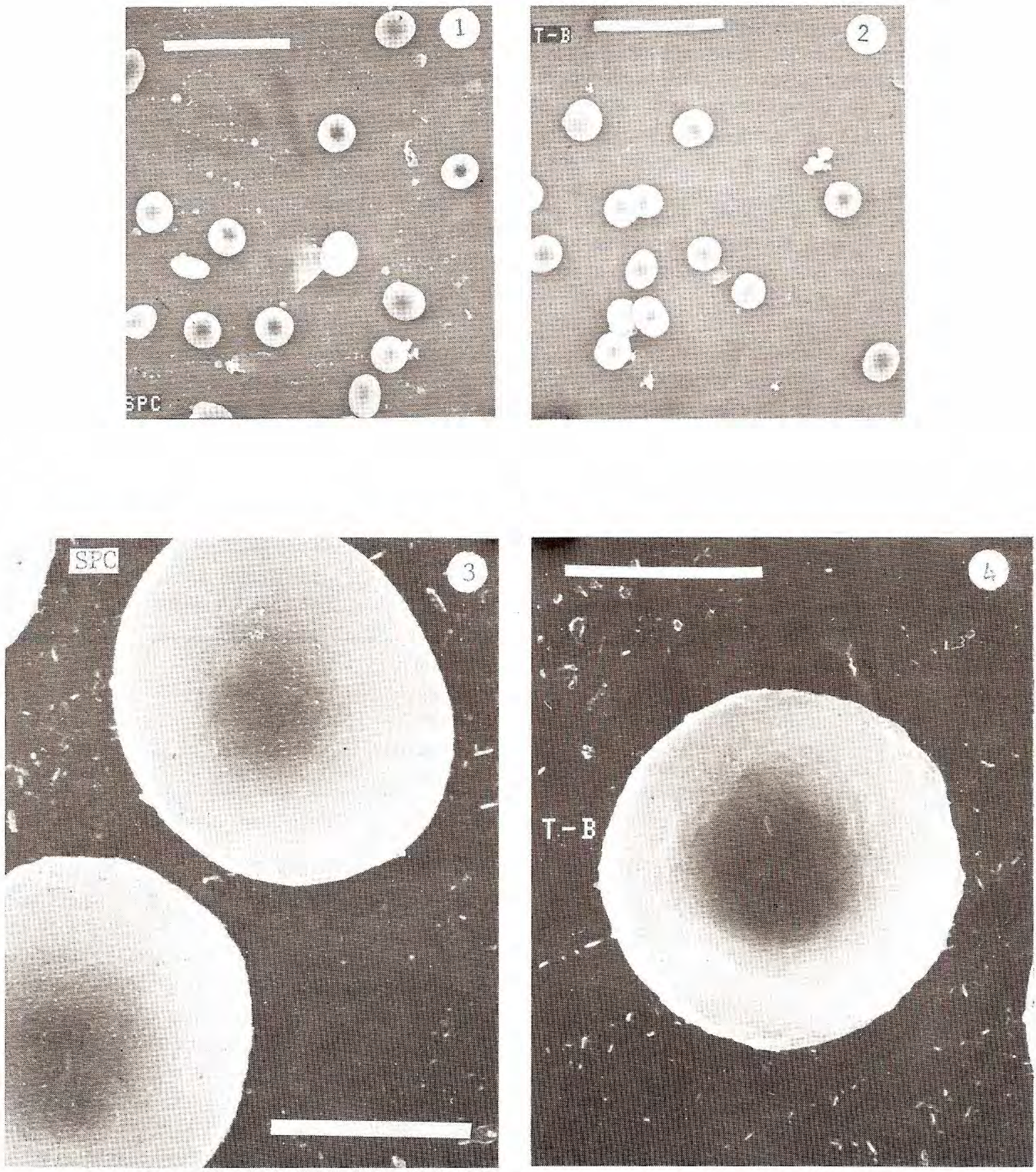

Figuras 1-4. Micrografías al MER de eritrocitos humanos procesados por el método de poli-L-lisina y secados en punto crítico (SPC) y terbutanol (T-B). No se observan alteraciones morfológicas evidentes. Figuras 1-2. 900 x; barra: $20 \mu \mathrm{m}$; Flguras 3-4. $10.000 \mathrm{x}$; barra: $3 \mu \mathrm{m}$. 

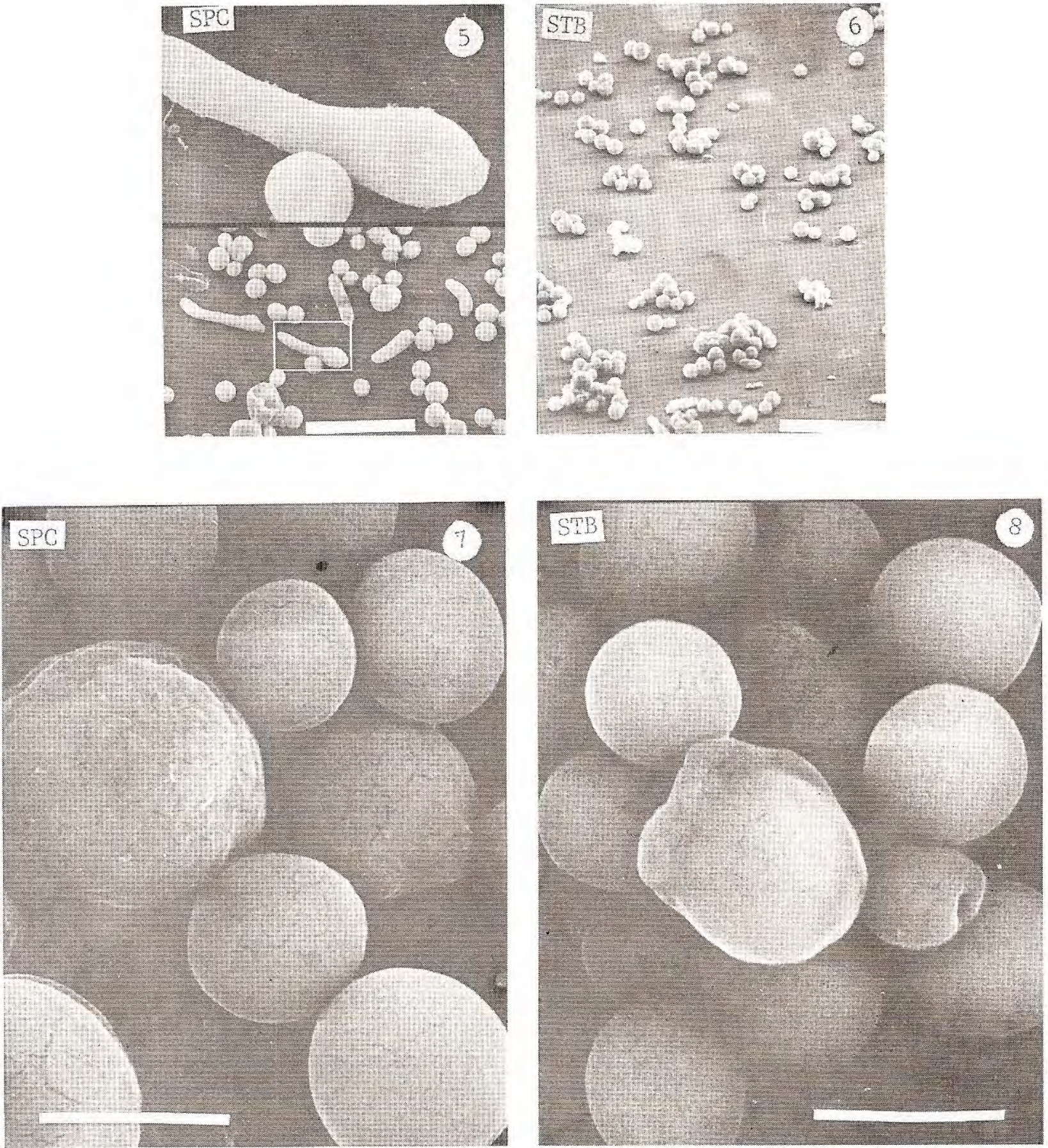

Figuras 5-8. Micrografías al MER de levaduras de Candida albicans procesados por el método de poli-L-lisina y secados en punto crítico (SPC) y terbutanol (STB). No se observan alteraciones morfológicas evidentes. Nótese la formación de pseudomicelio (figura 5) y los puntos de gemación (figuras 7-8). Figuras 5-6. $1500 \mathrm{x}$; barra $20 \mu \mathrm{m}$. Figuras 7-8. 10.000 x; barra $3 \mu \mathrm{m}$. 

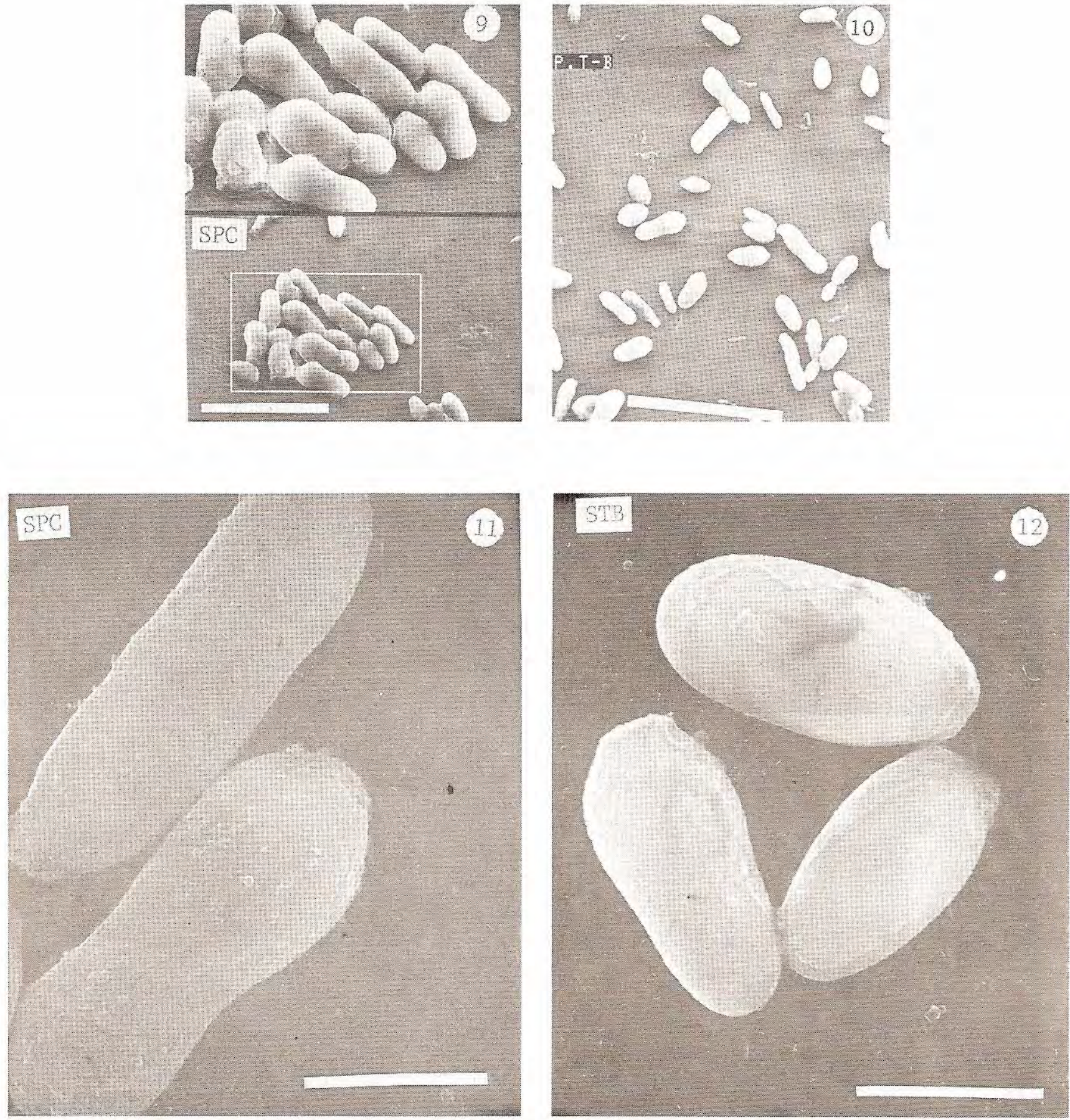

Figuras 9-12. Micrografías al MER de levaduras de Phaeoannelomyces werneckii procesados por el metodo de poli-L-lisina y secados en punto crítico (SPC) y terbutanol (STB). No se observan alteraciones morfológicas evidentes. Nótese los puntos de gemación (figura 9 ). Figuras 9-10. $1.500 \mathrm{x}$; barra $20 \mu \mathrm{m}$; Figuras 11-12. $10.000 \mathrm{x}$; barra $3 \mu \mathrm{m}$. 
reducción de $34,9 \%$ para SPC y $22,1 \%$ para STB. Después del proceso de secado, los eritrocitos y las levaduras se encogen, lo que se refleja en una disminución del volumen haciéndose más pequeños; estos cambios al parecer no sólo dependen del método de secado sino del uso o no de fijador y del tipo de fijador utilizado, pues, en ese mismo estudio, las células fijadas con GA pero no procesadas para MER, mostraron un aumento en el área del $60 \%$ aproximadamente. Nosotros hemos obtenido un ligero aumento del $3,3 \%$ para $C$. albicans y del $6-9 \%$, aproximadamente para $P$. werneckii. Probablemente el GA forma uniones cruzadas con proteínas de la membrana celular y con moléculas del citoplasma. En relación a los glóbulos rojos fijados $\mathrm{GA}$, no se obtuvo el incremento al igual que en las otras células estudiadas, debido a que la muestra analizada $(n=18)$ se consideró poco representativa. El mismo estudio demuestra cómo el GA al $2 \%$ transforma los eliptocitos en estomatocitos en un medio hipotónico cuando éste se mezcla rápidamente; pero, si se agrega lentamente es posible prevenir la deformación celular y la hemólisis.

A diferencia de otros estudios, no se evidenciaron alteraciones en la membrana celular como agujeros, invaginaciones o espículas; las células estudiadas mantuvieron su morfología inicial, lo cual concuerda con el mismo estudio donde se explica que la postfijación con Os previene el efecto osmótico de la fijación del GA, preservando la forma celular. Se ha sugerido un fenómeno de miniaturización por la presión del ambiente y del alto vacío acompañado de la evaporación de solventes, lo cual puede ser demostrado midiendo el volumen total de las células y comparándolo con el volumen seco de las mismas. Se ha demostrado también menor arrugamiento usando técnicas de aire seco en lugar de SPC. Boyde y Boyde (1980) muestran, además, cómo el uso del etanol como fluído intermedio en el SPC con $\mathrm{CO}_{2}$ presenta más arrugamiento del espécimen que el SPC usando freón 113 (tricloro-trifluro-etano, $\mathrm{F} 113$ ) $-\mathrm{CO}_{2}$, tanto en tejidos animales como vegetales, recomendando este último como líquido intermedio; en caso de usarse la técnica etanol- $\mathrm{CO}_{2}$ deben procesarse bloques pequeños de tejidos con tiempos prolongados de sustitución.

Estudios realizados en esporas fúngicas (Beckett et al., 1984) muestran que el tamaño de éstas al MER varían de acuerdo al procedimiento por el cual fueron preparadas, encontrándose mayor variación al emplear SPC (34\%) que FD. Se concluye, de nuevo, que el SPC produce mayor arrugamiento que FD (STB), coincidiendo con nuestro estudio en cada una de las células estudiadas. En tejidos vegetales, Boyde y Boyde (1980), haciendo ensayos en tomate mostraron una reducción en el volumen del $25 \%$. Nuestros hallazgos, además de confirmar los estudios anteriores, muestran que el porcentaje de reducción del tamaño varía con el tipo de espécimen. Los procesos de fijación química y deshidratación pueden causar cambios químicos y físicos en los componentes macromoleculares de las paredes celulares, membrana y citoplasma (Beckettet al., 1984). Una reducción de la constante dieléctrica en la cual está embebido el espécimen, junto con la remoción del agua celular pueden también contribuir a los cambios en el volumen.

Estas reducciones del volumen por SPC pueden ser reducidas en cierto grado, según Lee et al. (1979) y Boyde y Boyde (1980), mediante postfijaciones pre-SPC, con osmio (Os), acetato de uranilo $(\mathrm{AcU})$ y cloruro de cetilpiridio (CPC), que parecen tener un potencial útil, principalmente los dos últimos. Lee et al. (1979), usando cultivos de células musculares lisas obtuvieron una retención del $74 \%$ del volumen celular original, realizando un postratamiento con $\mathrm{AcU}$ después de la fijación con GA y postfijación con Os. El papel tanto del AcU como CPC no es muy claro, pero parece involucrar las acción de las cargas de los radicales acetato y cetilpiridio. Sin embargo, este método requiere de una visualización rápida al MER, pues el tejido tiende a una reducción rápida de volumen durante el almacenamiento. Los posteriores trabajos deben estar encaminados a investigar la acción de varios polianiones y policationes para formar uniones estables que ayuden a prevenir el colapso del espécimen, cuando el agua es reemplazada por solventes menos polares durante el SPC. 


\section{Conclusiones}

La disminución del tamaño de los especímenes durante el proceso de secado es la desventaja más grande que se presenta cuando se aplica el MER a estudios cuantitativos. Este estudio, así como otros anteriores, demuestran que el procesamiento más comúnmente usado de SPC con etanol- $\mathrm{CO}_{2}$, no es el mejor debido a la gran reducción en el volumen original del espécimen, aunque se preserva la morfología. EI SPC presenta mayor alteración del volumen y mayor arrugamiento que el STB; en ambos métodos de secado esa pérdida de volumen varía de un espécimen a otro, tanto en tejidos animales como vegetales, presentando estos últimos menor daño que los animales. Esta reducción entre los tejidos animales depende probablemente del contenido de agua celular y de la ausencia de pared que, en el caso de células vegetales, actúa como soporte. Se ha involucrado a la reducción del volumen un fenómeno de miniaturización, evaporación de solventes y presión del ambiente durante el proceso (alto vacío), dado por la reducción del volumen seco de la célula. El efecto del SPC se puede prevenir en parte con tratamientos posteriores a la postfijación, lo cual podría emplearse también en el STB. La fijación con GA tiene un efecto osmótico en los tejidos fijados produciendo ligeros aumentos en el volumen celular.

\section{Agradecimientos}

A la Agencia de Cooperación Internacional del Gobierno del Japón ('JICA), a la Unidad de Microscopía Electrónica y al Centro de Micología de la Facultad de Microbiología de la Universidad de Costa Rica.

\section{Referencias}

1. Beckett, A, N.D. Read \& R. Porter. Variations in fungal dimensions in relation to preparatory techniques for light microscopy and scanning electron microscopy. J Microsc 1984;136:87-95.

2. Boyde, A. \& S. Boyde. Further studies of specimen volume changes during processing for SEM: Including some plant tissue. Scanning Electron Microsc1980; II:117-124.

3. Eskelinen, S. \& P. Saukko. Effects of glutaraldehyde and critical point drying on the shape ans size of erythrocytes in isotonic and hypotonic media. $J$ Microsc 1983;130:63-71.

4. Hernández, F, H. Akahori \& F. Brenes. Soportes de vidrio recubiertos con poli-L-lisina para analizarmateriales biológicos en partículas tanto al microscopio electrónico de rastreo como al de transmisión. Biol Trop 1986;34:105-110.

5. Lee, R.M.K.W, R.E. Gardfield, J.B. Forrest \& E.E. Daniel.The effects of fixation, dehydration, and critical point drying on the size of cultured smooth muscle cells. Scanning Electron Microsc.1979; III:439-448. 